\title{
Marathon Map and its Utilization in City Tourism
}

\author{
Xiaoyan Liu ${ }^{\mathrm{a}, \mathrm{b}, \mathrm{c}} *$, Cheng Ye ${ }^{\mathrm{a}}$, Shuran Zhang ${ }^{\mathrm{a}}$ \\ ${ }^{a}$ School of Geography, Nanjing Normal University, Nanjing, 210023, China. liuxiaoyan@njnu.edu.cn.Cheng Ye, \\ 1149986165@qq.com.Shuran Zhang,1093052019@qq.com. \\ ${ }^{b}$ Key Laboratory of Virtual Geographic Environment (Nanjing Normal University), Ministry of Education, Nanjing,210023, China. \\ ${ }^{c}$ Jiangsu Center for Collaborative Innovation in Geographical Information Resource Development and Application, Nanjing, \\ 210023, China. \\ * Corresponding author
}

Keywords: Marathon Maps, Map Design, Quantitative Content Analysis, City Tourism

\begin{abstract}
:
Marathon running has become an obsession in China, with 22 marathon races in 2011 increasing to 400 in 2017 . Based on the Marathon annual report in 2017, marathon races will increase to above 1900 in 2020. More and more Chinese are traveling around the country to participate marathon races, which brings tremendous opportunities for the host cities, specifically for city tourism. A well-designed marathon map can not only help runners to learn detailed information for the races, but also help the tourists to learn natural and historical spots in the city. However, marathon maps and their designs are not examined in respect to cartography.
\end{abstract}

This study focused on full marathon race maps, collected 200 maps officially published by marathon organizers, inventoried the race information included in the maps, explored how many of these maps showing natural and historical scenic spots along the race, and analyzed common design elements of the maps using Quantitative Content Analysis (QCA), see table1. The goal of this study was to determine if the maps featured only the races or if they provided additional information to encourage tourist activities. A well designed marathon map can help both to the implementation of a race and to the creation of a sense of city.

\begin{tabular}{l|c|c|c|c|}
\hline \multirow{2}{*}{ Element } & \multicolumn{4}{|c}{ Representation } \\
\hline Race Course & 200 & 0 & 0 & Percentage \\
\hline Urban Features & 88 & 112 & 0 & $100.0 \%$ \\
\hline Road Network & 186 & 14 & 0 & $44.0 \%$ \\
\hline Mile Marker & 172 & 28 & 3 & $93.0 \%$ \\
\hline Direction Arrow & 134 & 60 & 6 & $86.0 \%(87.3 \%)$ \\
\hline Elevation Profile & 117 & 83 & 0 & $67.0 \%(69.0 \%)$ \\
\hline Suppliers & 167 & 33 & 0 & $58.5 \%$ \\
\hline QR Code & 6 & 194 & 0 & $83.5 \%$ \\
\hline Compass & 162 & 38 & 0 & $3.0 \%$ \\
\hline Text Message & 37 & 163 & 0 & $81.0 \%$ \\
\hline Tips: bracketed ratio indicates the presentation of maps which are not vague
\end{tabular}

Table 1. Results of these 200 Marathon race maps including race information and urban features.

In terms of the provision of race information, most maps use adjacent road network as base map, which can better show relative geographic location of race course in the city. But in some of these maps, complicate road networks were not simplified which reduced the representation of the course information. Mile marker and suppliers are often included in race maps as well. Mile markers helps runners to divide the track and reasonably set stage goals to obtain better results. 
At the same time, the increase of miles is intuitive to reflect the direction. In another word, mile marker and direction arrow are functionally coincident, and the former is more functionally comprehensive. Statistics show that the presentation ratio of mile marker is higher than that of direction arrow, which is in line with our expectations. Last but not least, less than $60 \%$ of these maps considered about elevation profile which has a significant impact on the runners' performance.

In terms of the expression of urban features, less than half of the maps developed to include natural, historical scenic spots and emphasized activities. Although map designers intend to attract the readers to pay attention to the features of host cities, no cartographic principles are employed in these maps. They fail to effectively attract the reader's attention and highlight urban features, undermines the uniform beauty of marathon map itself to some extent, see Table 2 . The most common design style is photograph, which can visually show the city scenery and help to promote city tourist activities. However, it will undermine the coordination of a complete marathon map, while generally the base map and POI points of marathon maps are in cartoon symbols, which is not the best way from cartographical perspective.

\begin{tabular}{|c|l|c|c|}
\hline \multirow{2}{*}{ Element } & \multicolumn{1}{|c|}{ Design Styles } & \multicolumn{2}{|c|}{ Usage of different Styles } \\
\cline { 3 - 4 } & & Map & Percentage \\
\hline \multirow{3}{*}{$\begin{array}{c}\text { Urban } \\
\text { Features }\end{array}$} & 1-photograph & 40 & $45.5 \%$ \\
\cline { 2 - 4 } & 2-Real Scene Graph & 14 & $15.9 \%$ \\
\cline { 2 - 4 } & 4-Colorful Silhouette & 25 & $28.4 \%$ \\
\cline { 2 - 4 } & 4-Cartoon Symbol & 6 & $6.8 \%$ \\
\cline { 2 - 4 } & 5-Comprehensive Styles & 3 & $3.4 \%$ \\
\hline
\end{tabular}

Table 2. Styles of thematic element design in 88 maps including urban features.

The results found that most race maps provide complete race information for the runners. But the maps are developed mostly for the courses, few of them take full advantage of effective cartographic principles and help to promote city tourist activities. 